\title{
Beyond the Border: A Comparative Literature Review on Communication Practices for Agile Global Outsourced Software Development Projects
}

\begin{abstract}
Software development is increasingly heading in the direction of combining agile software development practices and outsourcing software development to external vendors worldwide. The resulting agile global outsourced software development (AGOSD) projects are characterized by applying agile methods to distributed environments, which results in several problems for collaboration and coordination. Specifically, communication between the project participants has been found to be a major challenge in distributed environment. Therefore, our study investigates the problem of improving communication in distributed settings by identifying suitable communication practices for usage within AGOSD projects. Based on an extensive literature review, our study (1) provides an overview of adequate practices for usage in AGOSD and (2) points out differences to traditional communication practices of agile software development (ASD) projects used in collocated, non-distributed environments.
\end{abstract}

\section{Introduction}

In the past years, the usage of agile software development practices such as Scrum and Extreme Programming (XP) has increased considerably not only in traditional, collocated settings but also in distributed software development projects, wherein virtual teams from different locations jointly develop software solutions for organizations [1]. For example, a recent study on the usage of agile software development practices revealed that $80 \%$ of the study participants use agile software development practices in distributed teams, showing an increase of $35 \%$ from just two years earlier [1].

In parallel to the rise of agile software development practices, information technology outsourcing (ITO) has become a standard IT strategy for organizations, with the global ITO market estimated to be up to a total volume of $286 \mathrm{bn}$. USD in 2014 [2]. The combination of these two developments is currently leading to a widely observable phenomenon in industry, so-called agile global outsourced software development (AGOSD). Within AGOSD projects, client organizations outsource software development projects to external vendors, who are then using agile development practices within virtual project teams, with team members from all around the world working jointly on the project [3-5].

Many of these AGOSD projects encounter problems or are even failing completely [6-8]. One of the key reasons for project failure revealed by recent studies is non-working communication between the AGOSD project participants (e.g., client and vendor) [9-11]. In this context, it is important to note that communication practices within collocated, in-house agile software development (ASD) and AGOSD projects differ considerably from each other [12]. For example, Tanner and Wallace [13] showed that an insufficient implementation of communication practices in AGOSD projects (e.g., daily scrum meetings) due to working in different time zones, or different organizational cultures, is leading to information asymmetries and additional project complexity.

Even though the importance of and the differences between communication practices for inhouse ASD projects and AGOSD projects are recognized $[3,11,13,14]$, our knowledge on suitable practices for AGOSD remains scarce. We lack details about what specific communication practices are useful in AGOSD projects, why they are useful, and how we can implement them. Hence, the following research question guides our study: "How do communication practices for agile software development differ from communication practices for usage within agile global outsourced software development projects?"

To answer our research question, we conducted a structured and comparative literature review on communication practices within ASD and AGOSD projects based on the guidelines of Webster and Watson [15] and Levy [16]. We analyzed the existing literature on both ASD and AGOSD projects and identified a total set of 42 communication practices for usage within both ASD and AGOSD. After identifying and analyzing the practices, we conducted 
an in-depth comparison of the practices as regards their suitability for ASD and AGOSD. The result of our study is a comprehensive summary of communication practices suitable for AGOSD projects including 23 novel, AGOSD-specific practices as well as 8 ASD-based practices, which need to be adapted for the usage within AGOSD projects.

The remainder of the paper is structured as follows. The next section provides information on the theoretical background, specifically on distributed ASD and AGOSD. Section 3 introduces our research design with a description of the literature review and data analysis approach. Section 4 explains the results of our research with a focus on comparing the communication practices for ASD and AGOSD projects. Section 5 summarizes our findings, explains the limitations of the study, and provides guidance for future research. Finally, Section 6 concludes with a brief summary.

\section{Theoretical Background}

\subsection{Agile Software Development}

Traditional software development (SD) methods such as the waterfall approach follow several phases [17] with pre-defined outcomes and milestones for each phase [18]. In response to the large amounts of failed SD projects and to enable faster response times to changing customer requirements as well as shorter development cycles [18], ASD approaches have been developed [19]. Iterative processes, continuous interactions and communication between the client and the developer team as well as the continuous integration of the client into the software development process are the main differences between ASD approaches and traditional software development methods [20-23]. Familiar agile practices are Scrum and XP, but a wide range of other methods with different practices exist, and are used in projects [21, 23-25]. A recent study revealed that organizations are presently increasing their usage of such agile practices in general as well as the usage within an outsourcing context [1].

ASD is often proposed to be used in an environment in which there is the necessity to rapidly create change or to react quickly to changing requirements by applying smaller release cycles and continuous integration of the customer [26, 27]. In this context, it is not surprising that communication is a central aspect in an ASD project. The fundamental role of communication distinguishes ASD from traditional SD methods [9, 10, 28, 29]. This applies both to communication within the development team as well to communication with the customer. Hence, it is a vital task to improve communication between all participants of an ASD project $[10,30]$.

Communication in SD implicates that different people working on a common project agree to a common definition, share and provide information and coordinate their activities [10, 31]. Therefore the management of communication practices is seen as a success factor to achieve an ASD project's goal and emphasizes its important role [32]. Typical examples for agile communication practices are daily collaborations such as daily scrum meetings or pair programming, and the usage of "face-to-face" discussions instead of formal documentations, plans or models $[9,10]$.

\subsection{Agile Global Outsourced Software Development}

SD outsourcing, defined as the external sourcing of SD to an external provider [33], was first stated in 1989, when Kodak outsourced large parts of their SD capacities to IBM [34]. A large part of the ITO market is dedicated to SD-related outsourcing deals [35]. Contemporary vendors providing SD tasks are frequently based in countries such as India, China, East Europe and Latin America [19, 22]. With clients situated all around the word, including the U.S. and Europe, client organizations try to leverage expected lower wage levels and additionally gain access to well-trained technology specialists. This results in team members from client and vendor organizations from locations all around the world, with different cultural backgrounds, working together in virtual environments [23].

The combination of ASD with external outsourcing partners and virtual teams leads to AGOSD. AGOSD projects have to deal with additional challenges in the fields of control, coordination, technology as well as the integration of resources with different cultural backgrounds, languages and working attitudes [36]. Furthermore, they supposedly require an increase of communication during the SD process, a tighter integration of the (mostly far-away located) client as well as the incorporation of informal modes of control between an onshore client (e.g., in the U.S.) and an external, offshore SD team (e.g., in India) [6, 7, 14]. For example, past research identified the negative impact of distance on communication in AGOSD, which in turn has a negative effect on coordination [37]. In addition, AGOSD projects are expected to meet the requirements of cost reduction, 24 hours development, and faster release cycles [27]. 
However, in contrast to these expected benefits, AGOSD projects often require rework or fail completely [6-8, 38-40]. Communication issues between project members as well as with the client have been identified as one of the most important challenges within AGOSD [9-11, 29, 41].

\section{Research Design and Method}

We conducted a concept-driven and systematic literature review based on the approaches of Levy and Ellis as well as Webster and Watson [42, 43]. The review started with a keyword search on communication practices within global outsourced SD projects in general and AGOSD projects in particular, followed by a backward and forward search. To achieve high quality results, only journals and conference articles listed in the top MIS journals and conferences ranking provided by the AIS (http://aisnet.org/?JournalRankings) were used. We defined two search strings for the keyword search (see Table 1) to identify relevant articles in databases (EBSCOhost, INFORMS, ProQuest).

Table 1: Search Strings

\begin{tabular}{|c|l|l|}
\hline NO & Research field & \multicolumn{1}{c|}{ Search String } \\
\hline 1 & $\begin{array}{l}\text { Communication in } \\
\text { ASD projects }\end{array}$ & $\begin{array}{l}\text { (agil* OR SCRUM OR XP OR } \\
\text { „Extreme Programming“) AND } \\
\text { (,software develop*“ OR ,software } \\
\text { engineer*“) AND (communicat*) }\end{array}$ \\
\hline 2 & $\begin{array}{l}\text { Communication in } \\
\text { AGOSD Projects }\end{array}$ & $\begin{array}{l}\text { (agil* OR SCRUM OR XP OR } \\
\text { „Extreme Programming“) AND } \\
\text { (,,software develop*“ OR ,software } \\
\text { engineer*“) AND (distribut* OR } \\
\text { offshor* OR outsourc* OR nearshor* } \\
\text { OR nearshoring) AND } \\
\text { (communicat*) }\end{array}$ \\
\hline
\end{tabular}

There was no restriction for the publishing year of the articles. All search results were examined regarding title, abstract, and keywords. Within the resulting set of papers, we further identified relevant articles for our project purpose ("in scope") and dropped the others ("not in scope"). We subsequently proceeded with a reference, author and keyword backward search. Finally, a reference and author forward search identified our final set of articles for the data analysis phase.

In total, our final set of articles consists of 100 articles on communication practices in an agile environment. 25 articles describe the use of agile communication practices in general and 75 articles focus on positive effects of agile communication practices for projects.
In line with our overarching research question ("How do communication practices for agile software development differ from communication practices for the usage within agile global outsourced software development projects?"), our project followed a three-step data analysis approach (see Figure $1)$.

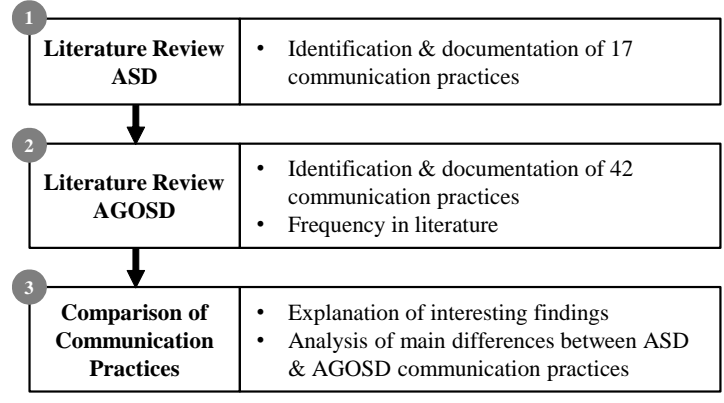

Figure 1: Analysis Approach

The results of the first and second step of our analysis are set down in two tables, in each case for communication practices in ASD and AGOSD. We used a concept matrix that is based on several categories to structure the presentation of the results. The approach allowed us to differentiate between three categories of practices used in AGOSD projects that additionally are included in presentation of results of step 2. Based on the concept matrix as well as both result tables we were able to perform step 3 in order to identify major findings and insights.

\section{Results}

\subsection{Communication in Agile Software Development Projects}

The literature review revealed a total of 17 communication practices within ASD projects, which are listed in Table 2. Due to space restrictions, a complete set of literature references has been neglected but is available from the authors on request.

Table 2: Communication Practices in ASD

\begin{tabular}{|l|l|}
\hline NAME & DESCRIPTION \\
\hline $\begin{array}{l}\text { Community of } \\
\text { practice }\end{array}$ & $\begin{array}{l}\text { Group of experts with a common interest } \\
\text { who want to enhance their know-how } \\
\text { deepening }[44,45]\end{array}$ \\
\hline $\begin{array}{l}\text { Continuous } \\
\text { communication }\end{array}$ & $\begin{array}{l}\text { Frequent communication using a variety } \\
\text { of technologies such as e-mail, mailing } \\
\text { list, IM systems, video conference and } \\
\text { screen sharing tools }[11,38,46]\end{array}$ \\
\hline
\end{tabular}




\begin{tabular}{|c|c|}
\hline NAME & \begin{tabular}{|l} 
DESCRIPTION \\
\end{tabular} \\
\hline $\begin{array}{l}\text { Continuous } \\
\text { integration }\end{array}$ & $\begin{array}{l}\text { Reducing configuration-management } \\
\text { issues by integrating source code and } \\
\text { building the entire system whenever } \\
\text { changes have made }[17,44,47]\end{array}$ \\
\hline $\begin{array}{l}\text { Creation of a (strict) } \\
\text { communication plan }\end{array}$ & $\begin{array}{l}\text { Maintaining multiple lines of communi- } \\
\text { cation \& establishing rules }[32,48]\end{array}$ \\
\hline $\begin{array}{l}\text { Creation of an open } \\
\text { environment }\end{array}$ & $\begin{array}{l}\text { The layout of the work area, e.g. desk } \\
\text { positions, impact productivity }[3,49]\end{array}$ \\
\hline Customer presence & $\begin{array}{l}\text { Customer representative is physically } \\
\text { located at the developing team [50] }\end{array}$ \\
\hline $\begin{array}{l}\text { Daily stand-up } \\
\text { meetings }\end{array}$ & $\begin{array}{l}\text { Daily and short meetings, wherein the } \\
\text { entire team discusses the project [3] }\end{array}$ \\
\hline $\begin{array}{l}\text { Storyboard / Task } \\
\text { Board }\end{array}$ & $\begin{array}{l}\text { Selected stories for an iteration are split } \\
\text { into tasks to deliver the story }[51,52]\end{array}$ \\
\hline Joint electronic & $\begin{array}{l}\text { Using a common technology in terms of } \\
\text { source control, user stories, product } \\
\text { backlog, source repository [53] }\end{array}$ \\
\hline Monthly meetings & $\begin{array}{l}\text { Face-to-face meetings e.g. to determine } \\
\text { the requirements priority or product } \\
\text { vision [20] }\end{array}$ \\
\hline Pair programming & $\begin{array}{l}\text { Developers are paired for producing } \\
\text { source code }[52,54]\end{array}$ \\
\hline Product backlog & $\begin{array}{l}\text { Vision of the software, including a list of } \\
\text { requirements, ordered by priority }[32,55]\end{array}$ \\
\hline $\begin{array}{l}\text { Scrum-of-scrum } \\
\text { meetings }\end{array}$ & $\begin{array}{l}\text { Meeting of Scrum masters wherein issues } \\
\text { and dependencies are clarified }[12,20]\end{array}$ \\
\hline $\begin{array}{l}\text { Standardized } \\
\text { processes and coding } \\
\text { standards }\end{array}$ & $\begin{array}{l}\text { Adherence of coding rules that emphasize } \\
\text { communication via source code }[47,56]\end{array}$ \\
\hline System metaphor & $\begin{array}{l}\text { Development is guided by a shared story } \\
\text { of how the software works. Serves as a } \\
\text { communication platform }[3,29]\end{array}$ \\
\hline $\begin{array}{l}\text { Test driven } \\
\text { development }\end{array}$ & $\begin{array}{l}\text { Test driven development, e.g. including } \\
\text { unit testing as well as automated } \\
\text { acceptance testing }[9,29,47]\end{array}$ \\
\hline User stories & $\begin{array}{l}\text { Use of compelling user stories that bind } \\
\text { together customers (who can express their } \\
\text { needs) as well as developers (who can } \\
\text { transform the story to design } \\
\text { requirements) }[12,44]\end{array}$ \\
\hline
\end{tabular}

The most frequently reported communication practice concerning ASD is dealing with face-to-face contacts between the projects' participants, for example, by means of a monthly meeting [20]. It is seen as a fundamental factor for success in ASD projects [32] and therefore is repeatedly mentioned in literature. In contrast, Scrum-of-scrum meetings, in which typically several Scrum masters (and perhaps a project leader) meet, is attached the least importance, although the practice can be used to distribute information between several teams in larger projects $[12,46]$.

\subsection{Communication in Agile Global Outsourced Software Development Projects}

Our literature review revealed a total set of 42 communication practices for AGOSD projects (see
Table 3). The table summarizes the practice name and the information about how a particular communication practice differs from the identified ASD practices in Section 4.1 (i.e., new AGOSDspecific practice or modified ASD practice, column "MOD" in Table 3).

Table 3 distinguishes between three categories of communication practices used in AGOSD projects. First, our list contains practices that are specific for use in AGOSD projects and consequentially are absent from the ASD practices given in Table 2 (23 practices in total, column "NEW" in Table 3). Second, we identified communication practices that, at first glance, are similar to their counterparts in ASD projects, but in fact are subjected to special modifications that make them suitable for use in AGOSD ( 8 practices in total). Third, we included ASD practices that can be used in AGOSD without further adaption (11 practices in total, column ASD in Table 3).

Table 3: Communication Practices in AGOSD

\begin{tabular}{|c|c|c|c|c|}
\hline NO & NAME & $\frac{z}{z}$ & $\stackrel{\hat{0}}{\mathrm{z}}$ & \\
\hline 1.1 & Establishing team member trust [57] & $\checkmark$ & & \\
\hline 1.2 & Synchronization of work hours [58] & $\checkmark$ & & \\
\hline 1.3 & $\begin{array}{l}\text { Use as many communication channels } \\
\text { as possible [57] }\end{array}$ & $\checkmark$ & & \\
\hline 1.4 & $\begin{array}{l}\text { Improved documentation (incremental, if } \\
\text { necessary and time saving) [58] }\end{array}$ & $\checkmark$ & & \\
\hline 1.5 & Rotation of employees [11] & $\checkmark$ & & \\
\hline 1.6 & Creation of a joint knowledge base [11] & $\checkmark$ & & \\
\hline 1.7 & $\begin{array}{l}\text { Groupware tools and other collaboration } \\
\text { technologies [59] }\end{array}$ & $\checkmark$ & & \\
\hline 1.8 & $\begin{array}{l}\text { Similar team compositions at } \\
\text { various locations [60] }\end{array}$ & $\checkmark$ & & \\
\hline 1.9 & $\begin{array}{l}\text { Trainings (language, communication, } \\
\text { technology and intercultural training) [61] }\end{array}$ & $\checkmark$ & & \\
\hline 1.10 & $\begin{array}{l}\text { Expert/ mediator rotation } \\
\text { (about various locations) [4] }\end{array}$ & $\checkmark$ & & \\
\hline 1.11 & $\begin{array}{l}\text { Provide project-specific guidelines and } \\
\text { standards (behavior, communication) [62] }\end{array}$ & $\checkmark$ & & \\
\hline 1.12 & Improvement of cooperation [63] & $\checkmark$ & & \\
\hline 1.13 & "One Team" - mentality [17] & $\checkmark$ & & \\
\hline 1.14 & Project management systems [64] & $\checkmark$ & & \\
\hline 1.15 & Avoidance of communication loops [65] & $\checkmark$ & & \\
\hline 1.16 & $\begin{array}{l}\text { IT infrastructure (high-speed data } \\
\text { connection) [66] }\end{array}$ & $\checkmark$ & & \\
\hline 1.17 & $\begin{array}{l}\text { Community of Practice } \\
\text { (know-how deepening) [44] }\end{array}$ & $\checkmark$ & & \\
\hline 1.18 & $\begin{array}{l}\text { Clarifying general questions in } \\
\text { advance of meeting [5] }\end{array}$ & $\checkmark$ & & \\
\hline 1.19 & Explicit targets (define milestones) [63] & $\checkmark$ & & \\
\hline 1.20 & Social networking [67] & $\checkmark$ & & \\
\hline 1.21 & Stakeholder analysis [68] & $\checkmark$ & & \\
\hline 1.22 & $\begin{array}{l}\text { Development of a project-specific } \\
\text { communication methodology [69] }\end{array}$ & $\checkmark$ & & \\
\hline 1.23 & $\begin{array}{l}\text { Generating a compatible ICT and media } \\
\text { convergence [70] }\end{array}$ & $\checkmark$ & & \\
\hline 2.1 & Continuous communication (E-Mail & & $\checkmark$ & \\
\hline
\end{tabular}




\begin{tabular}{|c|c|c|c|c|}
\hline NO & NAME & 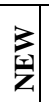 & $\stackrel{\hat{o}}{\mathrm{e}}$ & के \\
\hline & $\begin{array}{l}\text { mailing list, IM systems, video conference } \\
\text { and screen sharing tools [71] }\end{array}$ & & & \\
\hline 2.2 & $\begin{array}{l}\text { Expert/ manager/ mediator/ agents at } \\
\text { various sites (leadership briefings) [48] }\end{array}$ & & $\checkmark$ & \\
\hline 2.3 & $\begin{array}{l}\text { Usage of Web } 2.0 \text { tools (e.g. wikis, blogs, } \\
\text { virtual whiteboards) [14] }\end{array}$ & & $\checkmark$ & \\
\hline 2.4 & $\begin{array}{l}\text { Creation of a joint culture } \\
\text { (project vision and understanding) [72] }\end{array}$ & & $\checkmark$ & \\
\hline 2.5 & Usage of Task-tracking tools [73] & & $\checkmark$ & \\
\hline 2.6 & $\begin{array}{l}\text { Error-tracking tools (bug tracking, waste } \\
\text { identification) [11] }\end{array}$ & & $\checkmark$ & \\
\hline 2.7 & Pair-Programming across locations [11] & & $\checkmark$ & \\
\hline 2.8 & $360^{\circ}$ feedback (customer feedback) [74] & & $\checkmark$ & \\
\hline 3.1 & Weekly video conferences [38] & & & $\checkmark$ \\
\hline 3.2 & Monthly meetings (face-to-face) [75] & & & $\checkmark$ \\
\hline 3.3 & Daily Stand-Up-Meetings [76] & & & $\checkmark$ \\
\hline 3.4 & $\begin{array}{l}\text { Joint electronic workstations (source } \\
\text { control, user stories, product backlog, } \\
\text { repository) [53] }\end{array}$ & & & $\checkmark$ \\
\hline 3.5 & Customer Presence (at all locations) [14] & & & $\checkmark$ \\
\hline 3.6 & $\begin{array}{l}\text { Continuous integration } \\
\text { (Source code Integration) [17] }\end{array}$ & & & $\checkmark$ \\
\hline 3.7 & $\begin{array}{l}\text { Standardized processes and Coding } \\
\text { Standards [17] }\end{array}$ & & & $\checkmark$ \\
\hline 3.8 & $\begin{array}{l}\text { Creation of a (strict) communication plan } \\
\text { [3] }\end{array}$ & & & $\checkmark$ \\
\hline 3.9 & $\begin{array}{l}\text { Retrospectives and reviews } \\
\text { (shared and distributed) [59] }\end{array}$ & & & $\checkmark$ \\
\hline 3.10 & $\begin{array}{l}\text { Creation of an open environment } \\
\text { (e.g. the layout of the work area) [3] }\end{array}$ & & & $\checkmark$ \\
\hline 3.11 & $\begin{array}{l}\text { Scrum-of-Scrum Meetings (clarification of } \\
\text { issues and dependencies) [12] }\end{array}$ & & & $\checkmark$ \\
\hline \multicolumn{5}{|c|}{$\begin{array}{l}\text { Legend: NO = number of the communication practice, practices are ordered by } \\
\text { mathes in literature and the following criteria: } 1) \text { novel AGOSD-specific practices } 2 \text { ) } \\
\text { modified ASD practices 3) suitable ASD practices; NAME }=\text { name } / \text { short description } \\
\text { of the method incl. exemplary literature source; NEW }=\text { indicates a dedicated } \\
\text { AGOSD communication practice; MOD = indicates a communication practice to be } \\
\text { modified for use in AGOSD projects, ASD = indicates an ASD practices that can be } \\
\text { used in AGOSD without further adaption. }\end{array}$} \\
\hline
\end{tabular}

\subsection{A Comparison of Communication in Agile Software Development and Agile Global Outsourced Software Development}

Initially, we did not expect a high amount of communication practices specific to and dedicated for AGOSD. With a total of 23 practices, however, this category outnumbers the overall amount of identified communication practices in ASD. The most frequent reported AGOSD-specific communication practice is about the necessity of establishing "trust" between team members in order to improve communication. One of the reasons for this reportedly are the different cultural backgrounds of the involved team members, which are stated to make effective communication quite challenging $[6$, 14, 29, 77]. Moreover, a client may not have strong influence on the vendor in an outsourced environment, thus it may be difficult to persuade him to follow certain development practices [14]. For enhancing trust and building up stronger relationships, other practices are mentioned as well, for example, monthly or daily stand up meetings [3], continuous communication (especially with tools that are able to particular replace a face-to-face contact like video conferences), social networking (especially tools, which include conferencing techniques [67] ), establishing a "one-team" mentality, which increases motivation and trust or the delivery of code with the help of continuous integration (developers integrate their code and build the entire system for every made change) which leads to higher transparency and trust within the developer team $[17,78]$. In addition to the practices mentioned above the rotation of experts and mediators at various locations also provides an increase of trust by smoothing cultural misunderstandings, a customer presence at all locations can be a good option to build the main link between the two organizations (development team and client) [4, 48, 70]. To sum up, potential trust building communication practices seem to be essential regarding AGOSD whereas in ASD projects the aspect of trust plays a less important role.

Besides the already mentioned trust-related practices, the literature review revealed the synchronization of work hours within an AGOSD project as the second most frequent reported practice. This is related to the geographical distances and different time-zones, which are usually common in these projects $[29,58]$. Among other proposals in literature for handling the problem of "distance", synchronizing the work hours or aligning a team's workflow - for example by building smaller work units for each time-zone - seem to be quite common in literature [79].

Furthermore, an improved documentation is seen to be important within AGOSD, whereas improving means usage of lean documentation, which should be limited to what is absolutely needed [29, 79]. One idea is to produce incremental documentation, but in the end it is important to benefit from existing useful documents "...that take time but save more time" for all project participants [80]. This is interesting, because other practices follow the idea of facilitating knowledge sharing as well. For instance, the creation of a joint knowledge base plays a more important role in AGOSD than in ASD projects, thus there is higher management effort to be expected [11]. Knowledge sharing also includes usage of joint electronic workstations. The decision of using a common technology is quite essential, especially if different developer teams from various organizations are involved. For example, the decision of a joint source code repository, source code control or even integrated development environment determines to 
what extent the exchange of knowledge and grade of transparency can be guaranteed [53].

Finally, to support a better "sharing of knowledge", dealing with the common problem of "distance" and of course, establishing "trust", we found a remarkable number of advises in literature for using special technologies and software tools that enable or improve communication in globally distributed locations. Practices like E-Mail (e.g., mailing lists), instant messaging systems, and screen sharing tools as well as a regular use of Weekly video conferences and the Usage of Web 2.0 tools (e.g. wikis, blogs, virtual whiteboards) can be seen as the necessary elements for executing AGOSD projects basic $[11,14]$. Due to the nature of AGOSD projects this is not surprising because traditional ASD face-toface communication practices, for example a daily joint meeting, is not feasible in most of the environments [81]. Thus, the teams have to make use of these tools, to change from face-to-face to "faceto-interface" communication.

\section{Discussion}

\subsection{Summary of Findings and Implications}

Building upon our pre-defined research question, the main goal of this research project was the literature-based identification of suitable communication practices for AGOSD projects as well as the comparison of communication practices between ASD and AGOSD projects. Based on the results described in Section 4, we were generally able to provide answers to this research question and enhanced our knowledge on communication in AGOSD projects from both a theoretical as well as practical point of view:

(1) Providing future research directions for communication in AGOSD. Despite the known importance of communication for agile development projects in general and AGOSD projects in particular, there is so far no focused literature review on communication in AGOSD available. Our study closes this gap by providing an extensive literature review as well as future research directions based on the existing research on ASD as well as AGOSD projects. Building upon our work, and especially based on the comparison between communication in ASD and AGOSD, we are able to extend our understanding on communication in agile software development projects, which are outsourced and carried out by global teams from different organizations working jointly in virtual teams. Our list of communication practices revealed several interesting findings for communication in such projects, for example by identifying important factors like the "one-team" mentality, which is especially important, when working in joint teams coming from different organizations and ultimately different cultural backgrounds [17]. Furthermore, our literature review revealed the factor of creation of a joint knowledge base, which is up most important when creating joint, inter-organizational teams, who should work together and communicate on a daily basis, which is one of the key aspects of applying agile software development methods [11]. Nevertheless, we even found out that it is not a trivial task to identify and describe suitable communication practices in literature, much less to group them in appropriate cluster in order to reduce complexity. In our considerations of section 4.3, it is indicated that many of the mentioned practices could be grouped in a category dealing with "trust", "distance", "knowledge-management" or even "face-to-interface technologies". Nonetheless, there is still less knowledge of interdependencies between particular communication practices or even cluster, which are not considered in total.

Moreover we have recognized a lack of practices concerning large-scaled AGOSD projects. A lot of studies observed generally small projects, in which most of the team members are familiar with each other [14, 82]. But could not large-scaled AGOSD projects possibly underlie completely different problems? For example, Scheerer, Hildebrand and Kude [83] already mentioned that literature concerning necessary inter-team coordination in large-scale setup is scarce. Although the communication practice Scrum-of-Scrum Meetings $[12,46]$ is a typical method for improving coordination and communication in large-scaled agile development projects, our literature review showed that this topic is attached less importance.

Summing up, our literature review revealed that, despite our general knowledge on suitable communication practices for ASD and AGOSD projects, the exact relationship between the implementation of particular communication practices and AGOSD project success is still unknown. Hence, we would recommend to increase the IS communities' research endeavor on this important topic. This could be done for example by an evaluation of communication within AGOSD projects based on in-depth case study research. By applying such research methods in this context, we could further increase our understanding of how to implement the right kind of communication within AGOSD projects. 
(2) Providing a first overview of communication practices for AGOSD projects in practice. As already mentioned beforehand, our knowledge on suitable communication practices for AGOSD projects in practice remains scarce (see Section 1). Our study is, by certain means, able to cover this gap by providing a first overview of communication practices for AGOSD projects. This list of practices including references allows practitioners working in AGOSD projects to evaluate the existing practices for general suitability and implementation fit within their projects. Hence, based on our list, we are able to provide first-hand knowledge to practitioners, which needs to be amended by future research projects on this topic (e.g. the empirical analysis of particular communication practice suitability within AGOSD projects).

\subsection{Limitations and Future Research}

While we were able to provide sufficient answers to our research question and enhance our knowledge on communication in AGOSD projects, there are some limitations and corresponding future research directions that need to be acknowledged.

First, our research project took into account relevant journals in the IS domain (based on the recommendations of the AIS and VHB) only. We did not take into account outlets, which focus for example on communication (in general) or crosscultural studies. Hence, we cannot guarantee a complete analysis of the reference literature within our review. Nevertheless, due to the fact that agile software development in general and AGOSD projects in particular are a phenomenon in the field of IS, we are quite sure, that our results are generalizable to a certain extend. However, we would recommend further literature reviews on this topic to even increase the coverage of the existing research on this topic.

Second, we need to address the topic of the terms ASD and AGOSD as a limitation of our research. By starting our literature review with a keyword search and also by following the guidelines of Levy, Ellis and Webster, Watson [42, 43] in regards to forward and backward search, we tried to incorporate all past studies. Nevertheless, within the data analysis, we partially identified the incongruity of the term AGOSD. Some authors are speaking about agile software development (ASD), also when in reality looking at AGOSD projects, because their data sets include both ASD projects ("in-house") and AGOSD projects ("outsourced"). In these cases, the authors are using a mixed data set of ASD and AGOSD projects without looking at the differences between such projects. Based on this limitation, we would recommend further research, which explicitly focus on the comparison of ASD and AGOSD projects in the light of suitable communication practices.

\section{Conclusion}

With this paper, we identified suitable communication practices for AGOSD projects. With our study, we were able to provide an extensive overview about the research domain and foster further research on this important topic. Based on our literature review approach, we were able to process a large amount of already conducted research into our review, therefore further extending the scientific communities' knowledge about communication in AGOSD. We are confident that our study results provide an appropriate degree of generalizability and completeness. Nonetheless, we would emphasize further literature reviews and especially empirical studies on communication in AGOSD projects and especially further research on the identified gaps described within our study.

\section{References}

[1] VersionOne: The 9th Annual "State of Agile" Survey. Technical Report, Version One, Alpharetta, GA, U.S. (2015)

[2] Gartner, I.: Forecast Analysis: IT Outsourcing, Worldwide, 4Q13 Update. Gartner (2014)

[3] Yu, X., Petter, S.: Understanding agile software development practices using shared mental models theory. Information and Software Technology 56, (2014), pp. pp. 911-921

[4] Sutherland, J., et al.: Fully Distributed Scrum: Replicating Local Productivity and Quality with Offshore Teams. In: Proceedings of the 42nd Hawaii International Conference on System Sciences (HICSS), pp. 1-8, (2009)

[5] Sutherland, J.P.D., et al.: Distributed Scrum: Agile Project Management with Outsourced Development Teams. In: 40th Annual Hawaii International Conference on System Sciences (HICSS), pp. 1-8, (2007)

[6] Batra, D., et al.: Balancing Agile and Structured Development Approaches to Successfully Manage Large Distributed Software Projects: A Case Study from the Cruise Line Industry. Communications of the Association for Information Systems 27, (2010), pp. 15-33

[7] Kataja, A., Tuunanen, T.: Information systems development methods and reducing information asymmetry: a way to decrease project escalation in outsourcing? In: European Conference on Information Systems (ECIS), pp. pp. 1-8, (2006) 
[8] Herbsleb, J.D., Moitra, D.: Global software development. Software, IEEE 18, (2001), pp. 16-20

[9] Melnik, G., Maurer, F.: Direct Verbal Communication as a Catalyst of Agile Knowledge Sharing. In: Proceedings of the Agile Development Conference (ADC), pp. 21-31, (2004)

[10] Pikkarainen, M., et al.: The impact of agile practices on communication in software development. Empirical Software Engineering 13, (2008), pp. 303-337

[11] Bose, I.: Lessons Learned from Distributed Agile Software Projects: A Case-Based Analysis. Communications of the Association for Information Systems 23, (2008), pp. 619-632

[12] Pries-Heje, L., Pries-Heje, J.: Why Scrum Works: A Case Study from an Agile Distributed Project in Denmark and India. AGILE Conference (2011), pp. 20-28

[13] Tanner, M., Wallace, C.: Towards an Understanding of the Contextual Influences on Distributed Agile Software Development: A Theory of Practice Perspective. European Conference on Information Systems (ECIS 2012 Proceedings) (2012), pp. 1-13

[14] Batra, D.: Modified agile practices for outsourced software projects. Communications of the ACM 52, (2009), pp. $143-148$

[15] Webster, J., Watson, R.T.: Analyzing the Past to Prepare for the Future: Writing a Literature Review. MIS Quarterly 26, (2002), pp. 13-23

[16] Levy, Y.: A Systems Approach to Conduct an Effective Literature Review in Support of Information Systems Research. Informing Science Journal (2006),

[17] Phalnikar, R., et al.: Applying Agile Principles for Distributed Software Development. International Conference on Advanced Computer Control (2008), pp. 535-539

[18] Sommerville, I.: Software Engineering. Pearson Education Limited (2006)

[19] AgileAlliance: Agile manifesto.

(2001)

http://www.agilemanifesto.org

[20] Beck, K., et al.: Manifesto for Agile Software Development. (2001)

[21] Chow, T., Cao, D.-B.: A survey study of critical success factors in agile software projects. Journal of Systems and Software 81, (2008), pp. 961-971

[22] Dybå, T., Dingsøyr, T.: Empirical studies of agile software development: A systematic review. Information and Software Technology 50, pp. 833-859

[23] Stoica, M., et al.: Software Development: Agile vs. Traditional. Informatica Economică 17, (2013), pp. 64-76

[24] Kumar, G., Bhatia, P.K.: Comparative Analysis of Software Engineering Models from Traditional to Modern Methodologies. Advanced Computing \& Communication Technologies (ACCT), 2014 Fourth International Conference on (2014), pp. 189-196

[25] Kumar, G., Bhatia, P.K.: Impact of Agile Methodology on Software Development Process. International Journal of Computer Technology and Electronics Engineering (IJCTEE) 2, (2012), pp. 46-50

[26] Conboy, K.: Agility from First Principles: Reconstructing the Concept of Agility in Information Systems Development. Information Systems Research 20, (2009), pp. 329-354
[27] Erickson, J., et al.: Agile Modeling, Agile Software Development, and Extreme Programming: The State of Research. Journal of Database Management (JDM) (2005), pp. $88-100$

[28] Korkala, M., et al.: Combining agile and traditional: Customer communication in distributed environment. In: Šmite, D.M., Nils Brede; Ågerfalk, Pär J. (ed.) Agility Across Time and Space, pp. 201-216. Springer Berlin Heidelberg (2010)

[29] Hummel, M., et al.: The Role of Communication in Agile Systems Development. Business \& Information Systems Engineering 5, (2013), pp. 343-355

[30] Anderson, D.: Agile Management for Software Engineering: Applying the Theory of Constraints for Business Results (2003)

[31] Kraut, R.E., Streeter, L.A.: Coordination in software development. Communications of the ACM 38, (1995), pp. 69-81

[32] Holzmann, V., Panizel, I.: Communications Management in Scrum Projects. Proceedings of the European Conference on Information Management \& Evaluation. (2013), pp. 67-74

[33] Laudon, K.C., et al.: Wirtschaftsinformatik: eine Einführung. Pearson Deutschland GmbH (2010)

[34] Hall, J.A.: Financial performance, CEO compensation, and large-scale information technology outsourcing decisions. Journal of Management Information Systems 22, (2003), pp. 193-221

[35] Seddon, P.B., et al.: Does Domberger's theory of 'The Contracting Organization'explain why organizations outsource IT and the levels of satisfaction achieved? European Journal of Information Systems 16, (2007), pp. 237-253

[36] Yadav, V., et al.: Flexible Global software Development (GsD): Antecedents of success in Requirements Analysis. Journal of Global Information Management 17, (2009), pp. 31

[37] Carmel, E.A., Ritu: Tactical Approaches for Alleviating Distance in Global Software Development IEEE Software March/April, (2001), pp. 22-29

[38] Estler, H.-C., et al.: Agile vs. structured distributed software development: A case study. Empir Software Eng 19, (2014), pp. 1197-1224

[39] Hummel, M.M.: The Role of Shared Understanding in Distributed Scrum Development: An Empirical Analysis. International Conference on Information Systems 35, (2014), pp. 1-18

[40] Subasingha, M., et al.: Multi-Level Knowledge Transfer in Software Development Outsourcing Projects: The Agency Theory View. 33rd International Conference on Information Systems (2012), pp. 1-14

[41] Matalonga, S., et al.: Factors Affecting Distributed Agile Projects: A systematic review. International Journal of Software Engineering and Knowledge Engineering 23, (2013), pp. 1289-1301

[42] Levy, Y., Ellis, T.J.: A systems approach to conduct an effective literature review in support of information systems research. Informing Science: International Journal of an Emerging Transdiscipline 9, (2006), pp. 181-212

[43] Webster, J., Watson, R.T.: Analyzing the past to prepare for the future: Writing a literature review. 
Management Information Systems Quarterly 26, (2002), pp. 3

[44] Korn, H.-P., Berchez, J.P.: Agiles IT-Management in großen Unternehmen. Symposion Publishing $\mathrm{GmbH}$, Düsseldorf (2013)

[45] Paasivaara, M., Lassenius, C.: Communities of practice in a large distributed agile software development organization - Case Ericsson. Information and Software Technology 56, (2014), pp. 1556-1577

[46] Paasivaara, M., et al.: Using Scrum in Distributed Agile Development: A Multiple Case Study. Fourth IEEE International Conference onGlobal Software Engineering, 2009, ICGSE 2009 (2009), pp. 195-204

[47] Williams, L.: What agile teams think of agile principles. Communications of the ACM 55, (2012), pp. 71

[48] Vax, M., Michaud, S.: Distributed Agile: Growing a Practice Together. Agile 2008 Conference (2008), pp. 310 314

[49] De O. Melo, C.C., Daniela S.; Kon, Fabio; Conradi, Reidar: Interpretative case studies on agile team productivity and management. Information and Software Technology 55, (2013), pp. 412-427

[50] Greter, S., Keller, W.: AGILITÄT SKALIERT: EIN AGILES PROJEKT IN EINEM INTERNATIONALEN GROSSKONZERN. Objekt Spektrum (2012), pp. 44-50

[51] Meszaros, G.A., Janice: Adding Usability Testing to an Agile Project. In: AGILE Conference, pp. 289-294, (2006)

[52] Vidgen, R.W., Xiaofeng: Coevolving Systems and the Organization of Agile Software Development. Information Systems Research 20, (2009), pp. 355-376

[53] Young, C., Terashima, H.: How Did We Adapt Agile Processes to Our Distributed Development? Agile 2008 Conference (2008), pp. 304-309

[54] Karlström, D.R., Per: Integrating agile software development into stage-gate managed product development. Empir Software Eng 11, (2006), pp. 203-225

[55] Auf der Maur, R.: AGILES REQUIREMENTSENGINEERING: EIN ERFOLGSFAKTOR FÜR PRODUKTENTWICKLUNGEN. Objekt Spektrum (2012), pp. $71-76$

[56] Fitzgerald, B., et al.: Customising agile methods to software practices at Intel Shannon. European Journal of Information Systems 15, (2006), pp. 200-213

[57] Alzoubi, Y.I., Gill, A.Q.: Agile Global Software Development Communication Challenges: A Systematic Revies. Pacific Asia Conference on Information Systems (2014), pp. 1-14

[58] Ramesh, B., et al.: Can Distributed Software Development be Agile?: Three organizations studied here suggest the answer is "yes," when the unique characteristics of both environments are successfully blended. Communications of the ACM October 2006, (2006), pp. 41-46

[59] Hummel, M.: The Role of Shared Understanding in Distributed Scrum Development: An Empirical Analysis. International Conference on Information Systems 2014, (2014)

[60] Paasivaara, M., et al.: Distributed Agile Development: Using Scrum in a Large Project. IEEE International Conference (2008), pp. 87-95
[61] Hamsen, F., et al.: Agile Methods for Offshore Information Systems Development. First Information Systems Workshop on Global Sourcing: Services, Knowledge and Innovation (2007), pp. 1-20

[62] Sharp, J., Ryan, S.: A Research Framework for Investigating the Successful Configuration of Globally Distributed Agile Teams. AMCIS 2007 Proceedings. (2007), pp. 1-7

[63] Matalonga, S., et al.: FACTORS AFFECTING DISTRIBUTED AGILE PROJECTS: A SYSTEMATIC REVIEW. International Journal of Software Engineering \& Knowledge Engineering 23, (2013), pp. 1289-1301

[64] Hossain, E., et al.: Using Scrum in Global Software Development: A Systematic Literature Review. Fourth IEEE International Conference (2009), pp. 175-184

[65] Layman, L., et al.: Essential communication practices for Extreme Programming in a global software development team. Information and Software Technology 48, (2006), pp. 781-794

[66] Abbott, P., et al.: Innovation through collaborative partnerships: creating the MSN News for iPad app at VanceInfo Technologies. Journal of Information Technology Teaching Cases 3, (2013), pp. 16-28

[67] Shrivastava, S.V., Date, H.: Distributed Agile Software Development: A Review. Journal of Computer Science and Engineering 1, (2010), pp. 10-17

[68] Berger, H.: Outsourcing and Communications, the Role of Stakeholder Analysis - A Case Study in Practice. Proceedings of the Sixteenth Americas Conference on Information Systems (2012), pp. 1-11

[69] Bavani, R.: Critical Success Factors in Distributed Agile for Outsourced Product Development. Proceedings of CONSEG-09: International Conference on Software Engineering (2009), pp. 75-79

[70] Siakas, K., Siakas, E.: Agile Software Development in Distributed Environments. 16th European Software Process Improvement (EuroSPI 2009) (2009), pp. 19-31

[71] Korkala, M., Maurer, F.: Waste identification as the means for improving communication in globally distributed agile software development. Journal of Systems and Software (2014), pp. 122-140

[72] Scharff, C., et al.: Transitioning to Distributed Development in Students' Global Software Development Projects: The Role of Agile Methodologies and End-to-End Tooling. Software Engineering Advances (ICSEA), 2010 Fifth International Conference on, IEEE. (2010), pp. 388394

[73] Angioni, M., et al.: Defining a Distributed Agile Methodology for an Open Source Scenario. Proceedings of the 1st International Conference on Open Source Systems, July 11-15, 2005 Genova, Italy. (2005), pp. 1-5

[74] Frei, M.: Agil erfolgreicher führen: Warum agile Methoden ein neues Führungsverständnis erfordern. Objekt Spektrum (2014), pp. 58-63

[75] Lööf, T.: Agile outsourcing. A Case Study. Department of Applied Information Technology, pp. 10. Gothenburg University (2010)

[76] Sauer, J.: Agile Practices in Offshore Outsourcing: An Analysis of Published Experiences. Proceedings of the 29th information systems research seminar in Scandinavia, IRIS. 29, (2006), pp. 12-15 
[77] Dorairaj, S., et al.: Bridging cultural differences: a grounded theory perspective. Proceedings of the 4th India Software Engineering Conference. ACM, 2011. (2011), pp. 3-10

[78] Noordeloos, R., et al.: From RUP to Scrum in Global Software Development: A Case Study. 7th IEEE International Conference (2012), pp. 31-40

[79] Sharp, J.H., Ryan, S.D.: Best Practices for Configuring Globally Distributed Agile Teams. Journal of Information Technology Management 22, (2011), pp. 56-63

[80] Parnas, D.: Agile Methods and GSD: The wrong solution to an old but real prblem. Communications of the ACM 49, (2006), pp. 29

[81] Persson, J.S., et al.: Agile distributed software development: enacting control through media and context. Information Systems Journal 22, (2012), pp. 411-433

[82] Nevo, S., Chengalur-Smith, I.: Enhancing the performance of software development virtual teams through the use of agile methods: a pilot study. System Sciences (HICSS), 2011 44th Hawaii International Conference on. IEEE (2011),

[83] Scheerer, A.H., Tobias; Kude, Thomas: Coordination in Large-Scale Agile Software Development: A Multiteam Systems Perspective. In: 47th Hawaii International Conference on System Sciences (HICSS), pp. 4780-4788, (2014) 